\title{
Impact of Odd-Even Rationing of Vehicular Movement in Delhi on Air Pollution Levels
}

\author{
Keshav Singhania1, G. P. Girish ${ }^{2 *}$, Emodi Nnaemeka Vincent ${ }^{3}$ \\ ${ }^{1}$ Advisory Services, Ernst \& Young, Gurgaon, India \\ ${ }^{2}$ IBS Hyderabad, IFHE University, Hyderabad, India \\ ${ }^{3}$ College of Business, Law, and Governance, James Cook University, Cairns, Australia \\ Email: *gpgirish.ibs@gmail.com
}

How to cite this paper: Singhania, K., Girish, G.P. and Vincent, E.N. (2016) Impact of Odd-Even Rationing of Vehicular Movement in Delhi on Air Pollution Levels. Low Carbon Economy, 7, 151-160. http://dx.doi.org/10.4236/lce.2016.74014

Received: October 27, 2016

Accepted: November 25, 2016

Published: November 28, 2016

Copyright $\odot 2016$ by authors and Scientific Research Publishing Inc. This work is licensed under the Creative Commons Attribution International License (CC BY 4.0).

http://creativecommons.org/licenses/by/4.0/

\begin{abstract}
In this study, we investigate the impact of Odd-Even rationing of vehicles plying on the roads of the National Capital city of Delhi, India on air pollution levels by considering both residential and industrial areas of Punajbi Bagh, R.K. Puram, Anand Vihar, Mandir Marg, NSIT Dwarka and Shadipur of the city and have analyzed its impact by employing event study technique and by utilizing daily data of $\mathrm{NO}_{2}, \mathrm{SO}_{2}, \mathrm{O}_{3}$, $\mathrm{PM}_{10}$ and $\mathrm{PM}_{2.5}$. $\mathrm{A} \pm 15$ day window has been considered for our analysis to assess the impact on air pollution levels pre-odd even rationing and post-odd even rationing and has statistically investigated whether this bold move by the State Government of Delhi has helped in the reduction of air pollution levels in the city or not. With the State Government considering implementing Odd-Even rationing permanently, the present study is intended to provide insights to policy makers to take an informed decision and also facilitate in implementing future policies for controlling air pollution levels in the city.
\end{abstract}

\section{Keywords}

Pollution, Odd-Even Rationing, India, DPCC, CPCC

\section{Introduction}

Delhi, the National capital territory of India, has always been known world-wide for its rich historical sculptures, monuments and is now infamously known for its Air Pollution levels. World Health Organization [1] in their study in December 2014 found that 13 of the 20 most polluted cities of the world are from India and Delhi tops this infamous list by having six times more airborne particulate matter that are considered to be safe compared to normal level which is shocking, alarming and something which needs 
to be addressed immediately. The average $\mathrm{PM}_{2.5}$ levels in Delhi for Dec-Jan 2015 was 226 which was recorded by the US embassy compared to Beijing's 95 for the same period implying that New Delhi's air quality is almost twice as bad as that of Beijing's air quality. According to WHO's air quality guidelines the safe levels for PM is $20 \mu \mathrm{g} / \mathrm{m}^{3}$ (annual mean) for $\mathrm{PM}_{10}$ and that of $\mathrm{PM}_{2.5}$ is $10 \mu \mathrm{g} / \mathrm{m}^{3}$ (annual mean).

Air pollution in Delhi can be attributed to myriad of reasons such as: a) Human Activities such as emission from vehicles, emission from industries, construction and residential fuel burning, etc.; b) Natural Sources, such as dust, sea salt, etc.; c) Meteorological Conditions, such as Pre monsoon dust storm, Cold winds from Afghanistan and Pakistan pulls the emission from the densely urbanized Punjab and Haryana, where the straw is burned by the farmers in their fields; and d) City activities such as the burning of solid municipal waste, construction projects, etc. [2]. All of the above reasons combined together produce various gases in the in the air of the city, which are harmful above a certain limit. The gases which are present in the air of the city of Delhi are: a) Particulate Matter $10\left(\mathrm{PM}_{10}\right)$; b) Particulate Matter $25\left(\mathrm{PM}_{2.5}\right)$; c) Sulfur Dioxide $\left(\mathrm{SO}_{2}\right)$; d) Nitrogen Dioxide $\left(\mathrm{NO}_{2}\right)$; e) Ozone $\left(\mathrm{O}_{3}\right)$ [3].

The State Government of Delhi under the leadership of Chief Minister Mr. Arvind Kejriwal came up with a bold and unheard move of Odd-Even rationing of vehicles plying on the city roads i.e. Odd numbered vehicles plying on the roads on Odd calendar day and even numbered vehicles plying on the roads on even calendar day. In this study, we investigate the impact of Odd-Even rationing of vehicles plying on the roads of the National Capital city of Delhi, India on air pollution levels by considering both residential and industrial areas of Punajbi Bagh, R.K. Puram, Anand Vihar, Mandir Marg, NSIT Dwarka and Shadipur. With the State Government considering implementing Odd-Even rationing permanently, the present study is intended to provide insights to policy makers to take an informed decision and also facilitate in implementing future policies for controlling air pollution levels in the city.

The rest of the paper is structured as follows: In Section 2, we discuss the Air Pollutants found in Delhi's atmosphere and their possible impact on human health and some of the measures taken by Government to address this issue. In Section 3, we discuss our data, methodology and present our empirical findings of impact of Odd-Even rationing of vehicles plying on the roads on air pollution levels in Section 4 and conclude our study in Section 5.

\section{Air Pollutants}

First, Particulate Matter which is a complex mixture of both organic and inorganic substances suspended in air, affects the health of the people more than any other pollutant. The major components are sulfate, sodium, chloride, nitrates, ammonia, mineral dust, black carbon, and water. Particulates less than or equal to diameter of 10 microns are most health damaging which have the capability to penetrate and lodge deep into the lungs and can even cause cardiovascular and respiratory diseases as well as lung cancer [4]. Sulfur Dioxide $\left(\mathrm{SO}_{2}\right)$, a colorless gas with a sharp odor, is produced from the burn- 
ing of sulfur containing fossil fuels like coal \& oil, smelting mineral ore containing sulfur, power generation and motor vehicles. $\mathrm{SO}_{2}$ in combination with water causes sulfuric acid which is the main constituent of acid rain and the main cause of deforestation. This gas can affect the respiratory system and functions of lungs, irritation in eyes, mucus secretion, inflammation of the respiratory tract, aggravation of asthma and chronic diseases [4].

Nitrogen Dioxide $\left(\mathrm{NO}_{2}\right)$ is a toxic gas which causes significant inflammation in the airways, is the main source of nitrate aerosols, which forms an important fraction of $\mathrm{PM}_{2.5}$ and in the presence of the ultraviolet light of the ozone. The main sources of the emission of $\mathrm{NO}_{2}$ are heating, power generation and engines in vehicles and ships. There has been sufficient evidence that long-term exposure of $\mathrm{NO}_{2}$ leads to symptoms of bronchitis in asthmatic children. Ozone at ground level is one of the chief constituents of photochemical smog and should not be confused with ozone layer in the upper atmosphere. Ozone is formed with the reaction of sunlight with nitrogen oxide emitted from vehicles and industries, emission of volatile organic compounds emitted from vehicles, solvents and industry. Sunny days witness the highest levels of ozone. Breathing problem, trigger asthma, reduced lung functions are some of the side effects of ozone level increase [4].

In literature with respect to Indian context we find studies by [5] who focused on assessing the impact of field burning on aerosol mass loading and likely health implications by considering rural area of India. [6] in their study explored the role of citizen infrastructure in Mumbai and also the ecological priorities in the city of Mumbai, India. [7] in their study emphasized the necessity of spreading understanding among the people to curtail emissions during festivals such as Diwali and spread awareness about allied hazards. [8] in their study illustrate the connect between dust episodes and associated local scale regional aerosol optical properties by considering the region of Jaipur very close to Thar Desert of India. [9] in their study focused on influence of bursting of crackers/fireworks during Diwali fireworks on surface ozone $\left(\mathrm{O}_{3}\right)$, nitrogen oxides $\left(\mathrm{NO}_{\mathrm{x}}\right)$ and $\mathrm{BC}$ aerosol concentration over the city of Hyderabad, India for the time period between 2009 to 2011. [10] in their study examined the possible reasons for unusually low tropospheric column ozone which was observed in July 2002 over parts of eastern India when there was drought in the country.

To control the increasing pollution in the National Capital Territory of Delhi, various steps have been taken from time to time by the citizens, Government and the Honorable Supreme Court of India. In the writ petition (Civil) [No. 13029/1985] filed under Article 21 of the Constitution of India regarding air pollution in Delhi, M.C. Mehta Vs Union of India, Honorable Supreme Court of India passed several orders/directions to deal with the situation arising from time to time due vehicular pollution [3]. Some of them include: a) Elimination of leaded fuel from NCT of Delhi; b) Supply of pre-mix petrol for two stroke engines of two wheelers and auto; c) Replacement of all pre-1990 autos and taxis with new vehicles on clean fuels; d) No buses older than 8 years to ply other than that of CNG and clean fuel and entire bus fleet to be converted to CNG; e) India's largest Natural Gas processing and distribution company GAIL to expedite and 
expand from 9 to $80 \mathrm{CNG}$ outlets; f) $\mathrm{CPCB} / \mathrm{DPCC}$ to setup few more stations and strengthen the air quality monitoring stations for monitoring critical pollutants [2]. Apart from the above mentioned directives, various other directions were given to various other authorities to control the increasing air pollution levels in Delhi [11].

With the help of the directions given by the court and the constant support from the citizens of the state of Delhi it has been possible to implement maximum of the directions, resulting in the improvement of the situation, but still it being worse. The Government of Delhi has taken various steps to control the growing levels of pollution in the city, which includes, but not limiting to [12]: Phasing out of the commercial /transport vehicles which are older than 15 years, Switching over the entire public transport to CNG fuel mode, Implementation of Bharat Stage-IV/Euro-IV emission norms, Sulphur content in Diesel has been reduced up-to 50 PPM, 5 mechanized continuous monitoring stations have been installed by DPCC to monitor the air quality standard, VAT reimbursement of $12.5 \%$ allowed for switch of vehicles to clean fuel like CNG, entire city of Delhi declared as air pollution control locale under Air Act, Stringent emission norms for industries and thermal plants and Prohibition of the burning of leaves and plastic. Even after implementing all the above and other measures, the air quality in Delhi is deteriorating day by day.

To control the increasing pollution and improve the air quality standard in the city of Delhi, the present Government of Delhi, i.e., Aam Admi Party, lead by the Chief Minister Mr. Arvind Kejriwal is taking various steps. Last year lately, the Government decided to implement a test run of the Odd-Even formula for a 15 day, in which odd cars were allowed on the odd days and even on the even days. This was implemented from $1^{\text {st }}$ January, 2016 to $15^{\text {th }}$ January, 2016. This was a 15 day trial by the government in which was in effect for 12 hours daily, i.e., from 8 AM to $8 \mathrm{PM}$. Two wheelers and the commercial vehicles were kept out of the ambit of the odd even formula and were allowed on all the days. To help the people of the city in their daily schedule, the government reduced the frequency of the metros by increasing the number of trains by introducing 70 additional trips, augmenting the daily carrying capacity by over 6 lakh [13]. DTC roped in additional 3000 buses from the scheme, augmenting the carrying capacity of busses from 48 lakh to 60 lakh. Delhi has nearly 90 lakh registered vehicles, of which one third is cars and some 1500 new vehicles are added on daily basis [13].

\section{Research Methodology}

\subsection{Data}

Delhi air quality data was collected from the Delhi Pollution Control Committee and Central Pollution Control Board websites which is publicly available (Secondary data) for the time period between from $17^{\text {th }}$ December, 2015 to $30^{\text {th }}$ January, 2016 across all the stations for various parameters such as $\mathrm{NO}_{2}, \mathrm{SO}_{2}, \mathrm{O}_{3}, \mathrm{PM}_{10}$ and $\mathrm{PM}_{2.5}$.

\subsection{Event Window}

Use In order to gauge the effect of the event on the quality of air, a 45 day event win- 
dow has been setup, with 15 days being before the event period, 15 days after the event period and the event period of 15 days, during which the odd-even technique of controlling pollution was implemented by the Delhi Government.

\subsection{Method}

In order to study the impact of odd-even technique in the National Capital City of Delhi, we use daily average values for all the parameters, across all the stations. The average daily values are collected from the data provided by the Central Pollution Control Board and Ministry of Environment, Forests and Climate Change [14] [15].

To analyze the impact of the technique, mean is calculated for the event window, which is compared with the pre and post event mean to check whether there were any changes in the condition of pollution before the implementation and after the implementation of the technique with that of the event period. Even days mean and odd days mean has also been calculated which will help us assess whether a) Either the city has more number of registered vehicles of that particular group; or, b) That particular group pollutes more; or, c) Comparatively more number of vehicles were present on the road on those days. The findings of our study is compared with the standard set by National and WHO standards to analyze the deviation from the actual mean and to assess the impact of this exercise of Odd-even rationing on air pollution levels to facilitate future policy.

\section{Findings and Discussion}

Air pollution affects the life of all living creatures directly or indirectly. To control the growing impact of pollution in the city of Delhi, a major step was taken by the current Chief Minister of the National Capital Territory of Delhi by implementing an ODDEVEN scheme, in which odd vehicles were permitted to ply on road on the odd days and even on the even days. We analyze the impact of odd-even technique on the quality of air across different stations in Delhi, viz, Punjabi Bagh, R.K.Puram, Mandir Marg, Anand Vihar, NSIT Dwarka and Shadipur across various parameters of $\mathrm{NO}_{2}, \mathrm{SO}_{2}, \mathrm{O}_{3}$, $\mathrm{PM}_{10}$ and $\mathrm{PM}_{2.5}$ with the help of Event-Study technique.

An event window of +15 days and -15 days with the event duration of 15 days with a total of 45 days observation period window has been set-up to analyze the effect of odd even rationing on the movement of vehicles in Delhi on the air pollution levels. The analysis is sub-divided into Pre event, Post event, Event period, Odd day and Even day. The findings as mentioned in Table 1 to 6 highlight the main pollutant in the overall observation period, during odd \& even days, pre event, post event and during the event days. The findings are compared with the set National standards given by CPCB of India and World Health Organization standards to analyze the deviation from the set safety standards.

Table 1 shows the air pollution levels in the area of Punjabi Bagh which is majorly a residential area of the city of Delhi. Almost all the parameters of measuring the air pollution of an area were found out to be way above the National and the WHO standards. 
The pollution levels for $\mathrm{PM}_{10}$ and $\mathrm{SO}_{2}$ actually decreased during the odd-even tenure when compared to Pre-Event. For Punjabi Bagh the most harmful gas is $\mathrm{PM}_{10}$ which is $74 \%$ above the set safety standard, while $\mathrm{O}_{3}$ is the least harmful with value of $253.7 \%$ lesser than the set safety standard. $\mathrm{PM}_{2.5}$ is the second most harmful gas with a value 83.5\% higher than the national standard. $\mathrm{SO}_{2}$ has a favorable value of $198.9 \%$ lower than the standards. Maximum deviation can be observed in case of $\mathrm{PM}_{2.5}$ and $\mathrm{PM}_{10}$ for the area of Punjabi Bagh with values exceeding 93.14\% and $87.01 \%$ respectively with respect to WHO standards. The reason for high pollution figures in the area of Punjabi Bagh can be attributed to the on-going work of the Metro in the area. Due to construction, dust particulars along with the cement particulars are present in the air of the area, contributing to the increased particulate figures.

Table 2 shows the air pollution levels in the area of R. K. Puram, which is a residential area in the city of Delhi. Almost all the parameters were found out to be way above the National and the WHO standards. $\mathrm{PM}_{2.5}$ and $\mathrm{PM}_{10}$ turned out to be the most harmful gases in the R.K Puram area having values $83.97 \%$ and $73 \%$ above the set national standard and a deviation of $93.31 \%$ and $86.5 \%$ with respect to WHO standards. Table 3 shows the air pollution levels in the area of Anand Vihar, which is an industrial as well

Table 1. Air Pollution levels in the area of Punjabi Bagh, New Delhi.

\begin{tabular}{cccccc}
\hline Particulars & $\mathrm{PM}_{10}$ & $\mathrm{SO}_{2}$ & $\mathrm{NO}_{2}$ & $\mathrm{PM}_{2.5}$ & $\mathrm{O}_{3}$ \\
\hline Total Mean & 384.84 & 26.76 & 114.40 & 364.33 & 50.89 \\
Pre-Event Mean & 412.20 & 35.22 & 107.40 & 294.00 & 54.73 \\
Post-Event Mean & 367.60 & 20.80 & 111.33 & 409.29 & 38.07 \\
During Event Mean & 374.73 & 27.71 & 124.47 & 394.71 & 59.87 \\
Odd Mean (Event) & 375.00 & 26.50 & 122.13 & 401.00 & 68.25 \\
Even Mean (Event) & 374.43 & 29.33 & 127.14 & 386.33 & 50.29 \\
Percentage exceeding National Mean & $74.0 \%$ & $-198.9 \%$ & $30.1 \%$ & $83.5 \%$ & $-253.7 \%$ \\
\hline
\end{tabular}

In the absence of $24 \mathrm{hrs}$ mean for $\mathrm{NO}_{2}$ and $\mathrm{O}_{3}$, Actual mean has been considered in WHO standards. All the negative figures are favorable.

Table 2. Air Pollution levels in the area of R.K. Puram, New Delhi.

\begin{tabular}{cccccc}
\hline Particulars & $\mathbf{P M}_{10}$ & $\mathbf{S O}_{2}$ & $\mathbf{N O}_{2}$ & $\mathbf{P M}_{2.5}$ & $\mathrm{O}_{3}$ \\
\hline Total Mean & 370.31 & 43.42 & 102.49 & 374.40 & 59.96 \\
Pre-Event Mean & 393.73 & 43.73 & 98.40 & 343.60 & 54.47 \\
Post-Event Mean & 356.00 & 40.60 & 108.80 & 387.87 & 69.67 \\
During Event Mean & 361.20 & 45.93 & 100.27 & 391.73 & 55.73 \\
Odd Mean (Event) & 363.25 & 45.88 & 102.63 & 407.00 & 61.38 \\
Even Mean (Event) & 358.86 & 46.00 & 97.57 & 374.29 & 49.29 \\
Percentage exceeding National Mean & $73.00 \%$ & $-84.24 \%$ & $21.94 \%$ & $83.97 \%$ & $-200.2 \%$ \\
\hline
\end{tabular}

In the absence of $24 \mathrm{hrs}$ mean for $\mathrm{NO}_{2}$ and $\mathrm{O}_{3}$, Actual mean has been considered in WHO standards. All the negative figures are favorable. 
Table 3. Air Pollution levels in the area of Anand Vihar, New Delhi.

\begin{tabular}{cccccc}
\hline Particulars & $\mathrm{PM}_{10}$ & $\mathrm{SO}_{2}$ & $\mathrm{NO}_{2}$ & $\mathrm{PM}_{2.5}$ & $\mathrm{O}_{3}$ \\
\hline Total Mean & 509.11 & 24.95 & 115.09 & 409.58 & 14.84 \\
Pre-Event Mean & 676.13 & 23.36 & 125.53 & 370.40 & 17.07 \\
Post-Event Mean & 412.40 & 20.53 & 92.73 & 426.73 & 13.20 \\
During Event Mean & 438.80 & 30.87 & 127.00 & 431.60 & 14.27 \\
Odd Mean (Event) & 433.50 & 30.88 & 127.00 & 429.13 & 14.50 \\
Even Mean (Event) & 444.86 & 30.86 & 127.00 & 434.43 & 14.00 \\
Percentage exceeding National Mean & $80.36 \%$ & $-222.81 \%$ & $32.47 \%$ & $85.35 \%$ & $-112.6 \%$ \\
\hline
\end{tabular}

In the absence of $24 \mathrm{hrs}$ mean for $\mathrm{NO}_{2}$ and $\mathrm{O}_{3}$, Actual mean has been considered in WHO standards. All the negative figures are favorable.

as residential area in the city of Delhi. We find a huge drop in the $\mathrm{PM}_{10}$ values pre and post odd-even rationing. We find an increase in $\mathrm{SO}_{2}$ values in the odd-even car rationing period which is majorly attributed to vehicles. Anand Vihar being on the Delhi-Uttar Pradesh border witnesses a huge number of vehicular movements in the area. The polluting particulars are not limited to the city of Delhi but even the polluting particulars from the neighboring state is also there in the air of the city of Delhi, resulting in higher polluting figures. $\mathrm{PM}_{2.5}$ and $\mathrm{PM}_{10}$ turned out to be the most harmful gases in the Anand Vihar area having values $85.35 \%$ and $80.36 \%$ above the set national standard and a deviation of $93.9 \%$ and $90.18 \%$ with respect to WHO standards.

Table 4 shows the air pollution levels in the area of Mandir Marg, which is a residential area in the city of Delhi. Values of $\mathrm{PM}_{2.5}$ and $\mathrm{SO}_{2}$ witnessed a rise in the period of odd-even rationing. The values of $\mathrm{SO}_{2}$ was considerably higher on the Even days than those on the odd days which could be attributed to: a) More number of even number cars than that of the odd numbered cars; or, b) Excess vehicular movement on the even days to that of the odd days; or, c) Even cars are polluting more than the odd cars. $\mathrm{PM}_{2.5}$ and $\mathrm{PM}_{10}$ turned out to be the most harmful gases in the Mandir Marg area having values $82 \%$ and $68 \%$ above the set national standard and a deviation of $89.87 \%$ and $81.48 \%$ with respect to WHO standards. Air pollution levels in the area of NSIT Dwarka, which is a residential area in the city of Delhi shows that the value of $\mathrm{PM}_{2.5}$ increased from 192.5 in the pre-event period to 302.33 during the event phase. $\mathrm{SO}_{2}$, which is mainly due to the exhaustion from the vehicles, saw a major drop in the values from 23.93 to 7.73. Even though all the parameters are in the safety limit of the set national standard, none of the values falls in the safety limit of the WHO standards for NSIT Dwarka area which is a big concern.

Table 5 shows the air pollution levels in the area of Shadipur, which is an industrial area in the city of Delhi. We find that $\mathrm{PM}_{2.5}$ is the main pollutant in all the phases' of study. Due to the presence of the industries in the area, particulate matters are emitted due to combustion of solid and liquid fuels such as for power generation. There was not much of a change in the values of $\mathrm{SO}_{2}, \mathrm{NO}_{2}$ and $\mathrm{O}_{3}$. Except for $\mathrm{PM}_{2.5}$ all the other parameters have a value within the national safety limits. All the parameters show a fa- 
Table 4. Air Pollution levels in the area of Mandir Marg, New Delhi.

\begin{tabular}{cccccc}
\hline Particulars & $\mathbf{P M}_{10}$ & $\mathrm{SO}_{2}$ & $\mathrm{NO}_{2}$ & $\mathrm{PM}_{2.5}$ & $\mathrm{O}_{3}$ \\
\hline Total Mean & 317.69 & 24.97 & 90.33 & 336.47 & 38.76 \\
Pre-Event Mean & 298.69 & 28.00 & 69.11 & 290.00 & 49.91 \\
Post-Event Mean & 322.55 & 22.09 & 89.82 & 354.64 & 32.83 \\
During Event Mean & 335.27 & 25.58 & 110.00 & 370.17 & 35.07 \\
Odd Mean (Event) & 334.67 & 24.29 & 105.60 & 370.86 & 40.71 \\
Even Mean (Event) & 336.00 & 27.40 & 114.40 & 369.20 & 29.43 \\
Percentage exceeding National Mean & $68.52 \%$ & $-220.41 \%$ & $11.44 \%$ & $82.17 \%$ & $-364.44 \%$ \\
\hline
\end{tabular}

In the absence of $24 \mathrm{hrs}$ mean for $\mathrm{NO}_{2}$ and $\mathrm{O}_{3}$, Actual mean has been considered in WHO standards. All the negative figures are favorable.

Table 5. Air Pollution levels in the area of Shadipur, New Delhi.

\begin{tabular}{cccccc}
\hline Particulars & $\mathrm{PM}_{10}$ & $\mathrm{SO}_{2}$ & $\mathrm{NO}_{2}$ & $\mathrm{PM}_{2.5}$ & $\mathrm{O}_{3}$ \\
\hline Total Mean & 19.79 & 77.53 & 264.74 & 31.62 & 19.79 \\
Pre-Event Mean & 22.50 & 82.86 & 217.00 & 32.07 & 22.50 \\
Post-Event Mean & 14.60 & 69.17 & 289.40 & 30.93 & 14.60 \\
During Event Mean & 22.64 & 79.36 & 286.07 & 31.87 & 22.64 \\
Odd Mean (Event) & 20.86 & 84.14 & 288.57 & 30.75 & 20.86 \\
Even Mean (Event) & 24.43 & 74.57 & 283.57 & 33.14 & 24.43 \\
Percentage exceeding National Mean & $-304.23 \%$ & $-3.19 \%$ & $77.34 \%$ & $-469.22 \%$ & $-304.23 \%$ \\
\hline
\end{tabular}

In the absence of $24 \mathrm{hrs}$ mean for $\mathrm{NO}_{2}$ and $\mathrm{O}_{3}$, Actual mean has been considered in WHO standards. All the negative figures are favorable.

vorable result except for $\mathrm{PM}_{2.5}$ which is $90.56 \%$ above the safety limits as per WHO standards.

Overall from our empirical analysis we find that the major pollutant in the national capital city of Delhi is $\mathrm{PM}_{2.5}$ followed by $\mathrm{PM}_{10}$. The value of $\mathrm{PM}_{2.5}$ is seen as high as 426.7 in Anand vihar, while the highest value recorded for $\mathrm{PM}_{10}$ was 676.1 in the same area. Across all areas in the city, Anand Vihar witnessed the highest pollution figures across all the set parameters.

\section{Conclusions}

In the study, we investigate the impact of Odd-Even car rationing in the city of Delhi for the first phase (January 2016) in the areas of Punjabi Bagh, R.K. Puram, Anand Vihar, Mandir Marg, NSIT Dwarka and Shadipur by applying the event study technique for quantifying the results into pre event, post event and the even phase period. We find that the maximum pollution level is seen in the area of Anand Vihar where the major pollutant was $\mathrm{PM}_{10}$. The major pollutant in the city was found out to be $\mathrm{PM}_{2.5}$ followed by $\mathrm{PM}_{10}$. There are a various reasons that contribute to high pollution figures in the city of Delhi like the vehicles of the city, factories, construction of metro, vehicles coming 
from the near-by city, burning of wheat stubble in Haryana, pollution from neighboring states, municipal solid waste burning, etc.

UNICEF on $14^{\text {th }}$ November 2016 mentioned that it is a wakeup call for all of us citing deterioration air quality levels in New Delhi. We recommend the following actions to be taken in order to control the pollution in the city: a) Banning the diesel vehicles; b) Offering subsidy on the conversion of diesel/petrol vehicles to CNG; c) Banning the entry of polluting vehicles in the city from the neighboring state or levying high entry tax on it; d) Banning the cars plying on the road basis the days, for example: Monday (No Two Wheelers), Tuesday (No Heavy Vehicles), Wednesday (No Commercial Cars), Thursday (No Private Cars), Friday (No Three-wheelers) and Saturday (Only CNG Vehicles); e) Banning the burning of wheat stubble in Haryana and Uttar Pradesh by the respective government. It was banned on May 6, 2015 by the Haryana Government but the same has been burned this year as well; f) Neighboring states like Haryana and Uttar Pradesh should take adequate actions and set-up proper laws to control the pollution in their respective states as the same comes to Delhi by mixing in the air; g) Removing the road dust from both the side of the road by making proper road like in the NDMC area (Ashoka Road, Prithviraj Road, Race Course Road, Tees January Marg, Akbar Road, Janpath, etc.).

\section{References}

[1] World Health Organization International (2016) http://www.who.int/en/

[2] Delhi Pollution Control Committee (2016) http://www.dpcc.delhigovt.nic.in/

[3] Central Pollution Control Board (2016) http://cpcb.nic.in/

[4] Weidemann, E., Andersson, P.L., Bidleman, T., Boman, C., Carlin, D.J., Collina, E., Cormier, S.A., Gouveia-Figueira, S.C., Gullett, B.K., Johansson, C., Lucas, D.D., Lundin, L., Lundstedt, S., Marklund, S., Nording, M.L., Ortuño, N., Sallam, A.A., Schmidt, F.M. and Jansson (2016) $14^{\text {th }}$ Congress of Combustion By-Products and Their Health Effects-Origin, Fate, and Health Effects of Combustion-Related Air Pollutants in the Coming Era of Bio-Based Energy Sources. Environmental Science and Pollution Research, 23, 8141-8159.

[5] Nirmalkar, J. and Deb, M.K. (2016) Impact of Intense Field Burning Episode on Aerosol Mass Loading and Its Possible Health Implications in Rural Area of Eastern Central India. Air Quality, Atmosphere, and Health, 9, 241-249. https://doi.org/10.1007/s11869-015-0330-y

[6] Sperling, J., Romero-Lankao, P. and Beig, G. (2016) Exploring Citizen Infrastructure and Environmental Priorities in Mumbai, India. Environmental Science and Pollution Research, 60, 19-27. https://doi.org/10.1016/j.envsci.2016.02.006

[7] Majumdar, D., Rao, P.S., Chakraborty, B.D. and Srivastava, A. (2015) Effects of Unregulated Anthropogenic Activities on Mixing Ratios of Volatile Organic Air Pollutants-A Case Study. The Journal of the Air \& Waste Management Association, 65, 1094-1103. https://doi.org/10.1080/10962247.2015.1062815

[8] Verma, S., Payra, S., Gautam, R., Prakash, D., Soni, M., Holben, B. and Bell, S. (2013) Dust Events and Their Influence on Aerosol Optical Properties over Jaipur in Northwestern India. Environmental Monitoring and Assessment, 185, 7327-7342.

https://doi.org/10.1007/s10661-013-3103-9 
[9] Yerramsetti, V.S., Sharma, A.R., Navlur, G.N., Rapolu, V., Dhulipala, N.S.K.C. and Sinha, P.R. (2013) The Impact Assessment of Diwali Fireworks Emissions on the Air Quality of a Tropical Urban Site, Hyderabad, India, during Three Consecutive Years. Environmental Monitoring and Assessment, 185, 7309-7325. https://doi.org/10.1007/s10661-013-3102-x

[10] Ghude, S.D., Kulkarni, S.H., Kulkarni, P.S., Kanawade, V.P., Fadnavis, S., Pokhrel, S., Jena, C., Beig, G. and Bortoli, D. (2011) Anomalous Low Tropospheric Column Ozone over Eastern India during the Severe Drought Event of Monsoon 2002: A Case Study. Environmental Science and Pollution Research, 18, 1442-1455. https://doi.org/10.1007/s11356-011-0506-4

[11] Delhi District Courts (2016) http://delhicourts.nic.in/

[12] Government of NCT of Delhi (2016) http://delhi.gov.in/

[13] Delhi Traffic Police (2016) http://delhitrafficpolice.nic.in/

[14] The Ministry of Environment, Forests and Climate Change (2016) http://www.moef.nic.in/

[15] Times of India (2016)

http://articles.economictimes.indiatimes.com/2015-05-06/news/61865252_1_stubble-polluti on-control-board-happy-seeder

Submit or recommend next manuscript to SCIRP and we will provide best service for you:

Accepting pre-submission inquiries through Email, Facebook, LinkedIn, Twitter, etc. A wide selection of journals (inclusive of 9 subjects, more than 200 journals)

Providing 24-hour high-quality service

User-friendly online submission system

Fair and swift peer-review system

Efficient typesetting and proofreading procedure

Display of the result of downloads and visits, as well as the number of cited articles Maximum dissemination of your research work

Submit your manuscript at: http://papersubmission.scirp.org/

Or contact lce@scirp.org 